\title{
A role for CKII phosphorylation of the Cactus PEST domain in dorsoventral patteming of the D rosophila embryo
}

\author{
Zhi-Ping Liu, Rene L. Galindo, and Steven A. Wasserman ${ }^{1}$ \\ Department of Molecular Biology and Oncology, University of Texas Southwestern Medical Center at Dallas, \\ Dallas, Texas 75235-9148 USA
}

\begin{abstract}
Regulated proteolysis of Cactus, the cytoplasmic inhibitor of the Rel-related transcription factor Dorsal, is an essential step in patteming of the D rosophila embryo. Signal-induced Cactus degradation frees Dorsal for nuclear translocation on the ventral and lateral sides of the embryo, establishing zones of gene expression along the dorsoventral axis. Cactus stabi lity is regulated by amino-terminal serine residues necessary for signal responsiveness, as well as by a carboxy-terminal PEST domain. We have identified D rosophila casein kinase II (CKII) as a Cactus kinase and shown that CKII specifically phosphorylates a set of serine residues within the Cactus PEST domain. These serines are phosphorylated in vivo and are required for wild-type Cactus activity. Conversion of these serines to alanine or glutamic acid residues differentially affects the levels and activity of Cactus in embryos, but does not inhibit the binding of Cactus to Dorsal. Taken together, these data indicate that wild-type axis formation requires CKII-catalyzed phosphorylation of the Cactus PEST domain.
\end{abstract}

[Key Words: proteolysis; Rel; NF-кB; signal transduction; Dorsal]

Received May 28, 1997; revised version accepted October 16, 1997.

A nuclear concentration gradient of the transcription factor Dorsal defines the dorsoventral axis of the Drosophila embryo (for review, see Chasan and Anderson 1993). Dorsal is a member of the Rel family of proteins that includes mammalian N F-кB, the avian oncogene $\mathrm{v}$ rel, and the cellular proto-oncogene c-rel (Steward 1987; for review, see Verma et al. 1995). Transcriptional activity of Rel proteins is controlled at the level of subcellular localization. More specifically, ankyrin-repeat containing inhibitory proteins such as Cactus, $I \kappa B \alpha$, and $I \kappa B \beta$ retain Rel proteins in the cytoplasm by direct interaction. On stimulation, signal transduction targets the inhibitors for degradation, freeing the Rel-proteins for translocation into nuclei.

A maternally encoded signal transduction pathway directs the asymmetric nuclear translocation of Dorsal in the embryo (for review, see Chasan and Anderson 1993). A protease cascade active in the ventral portion of the extraembryonic space cleaves, and thereby activates, the Spätzle protein. Spätzle then acts as an extracellular ligand, binding the transmembrane receptor Toll. This asymmetric activation of Toll initiates intracel lular signal transduction via the protein kinase Pelle that drives Cactus degradation, thereby freeing Dorsal for nuclear

${ }^{1}$ Corresponding author.

E-MAIL Stevenw@hamon.swmed.edu; FAX (214) 648-1196. import. On translocation into ventral and Iateral nuclei, Dorsal establi shes embryonic polarity by activating transcription of ventral-specific genes while repressing dorsal-specific loci.

The pathway governing subcellular localization of Drosophila Dorsal displays striking similarities to at least one pathway that controls the partitioning of mammalian NF-кB between the nucleus and cytoplasm (Wasserman 1993; Cao et al. 1996). At least four of the proteins in the Drosophila dorsoventral pathway-Toll, Pelle, Dorsal, and Cactus-have structural and functional counterparts in the response of Iymphocytes and other cell types to the cytokine interleukin-1 (IL-1) - the IL-1 receptor, the IL-1 receptor associated kinase (IRAK), $\mathrm{N} F-\kappa \mathrm{B}$, and $\mathrm{I} \kappa \mathrm{B} \alpha$.

In both the invertebrate and vertebrate Rel-protein pathways, phosphorylation of the inhibitor appears to be a critical step in signal transduction (for review, see Baeuerle and Baltimore 1996). Signal-dependent degradation of $I_{\kappa} B \alpha$ requires phosphorylation of a pair of serine residues, followed by $I \kappa B \alpha$ ubiquitination and proteasomemediated degradation (Palombel la et al. 1994; Brown et al. 1995; Traenckner et al. 1995). Signal transduction to Cactus requires two pairs of serine residues in a similar sequence context; mutation of these four serines to alanines blocks signal-mediated degradation of Cactus (Reach et al. 1996).

The structural and functional similarities between Cactus and $\mathrm{I}_{\kappa} \mathrm{B} \alpha$ extend to their carboxyl termini. Both 
proteins contain a carboxy-terminal PEST sequence. Such domains, rich in proline $(P)$, glutamate $(E)$, serine $(\mathrm{S})$, and threonine $(\mathrm{T})$ residues, are thought to induce rapid protein turnover (Rogers et al. 1986; Rechsteiner and Rogers 1996). Consi stent with this hypothesis, deletion of the PEST-containing regi on from $1 \kappa B \alpha$ leads to a substantial increase in steady-state protein levels (Lin et al. 1996; Van Antwerp and Verma 1996). PEST-deleted forms of both Cactus and $\mathrm{I} \kappa \mathrm{B} \alpha$ are still rapidly degraded in response to signaling, but the efficiency of signal transduction is reduced (Belvin et al. 1995; Baeuerle and Baltimore 1996; Bergmann et al. 1996; Reach et al. 1996). It is not known whether this diminution in signaling results sol ely from an increase in the number of inhibitor molecules to be degraded or as well as from a change in the responsiveness of individual mol ecules to the signaling apparatus.

In the course of investigating Cactus regulation, we have purified a kinase that specifically phosphorylates the PEST region of Cactus. We have identified this kinase as Drosophila casein kinase II (CKII) and have mapped the phosphorylation sites to a group of three serines. We have shown that these Cactus PEST domain serines are phosphorylated in embryos. We have al so explored the effect of mutating these serines on signal transduction to the Dorsal-Cactus complex, on Cactus binding to Dorsal, and on the levels of Cactus in embryos. Taken together, our results indicate that CKII phosphorylation of Cactus is required for efficient signaling to the Dorsal-Cactus complex and that phosphorylation modulates PEST-mediated protein degradation in vivo.

\section{Results}

An in-gel assay detects Drosophila CKII as a Cactus kinase

Cactus is a phosphoprotein in the developing embryo and protein kinase activity is required in the signaling pathway that governs Cactus degradation (Kidd 1992; Shelton and Wasserman 1993). To identify the kinase(s) responsible for phosphorylation of Cactus in embryos, we performed an in-gel assay (Hibi et al. 1993). We prepared extracts from 0 - to 3-hr embryos and subjected them to electrophoresis in an SDS-polyacrylamide gel containing hexahistidine-tagged Cactus ( $\mathrm{His}_{6}-\mathrm{Cactus)}$ incorporated into the gel matrix. Following electrophoresis, resolved proteins were allowed to renature and were then assayed for phosphotransferase activity in the presence of $\left[\gamma^{-32} \mathrm{P}\right]$ ATP.

The in-gel Cactus kinase assay revealed a single radiolabeled species with an apparent molecular weight (mw) of 37,000 (Fig. 1A,B). No radiolabeled band was detected when $\mathrm{His}_{6}-\mathrm{C}$ actus was omitted from the gel matrix (data not shown), showing that Cactus, and not the kinase itself, was the substrate for the in-gel activity. The in-gel activity was independent of the embryonic signaling state; we obtained identical results by use of extracts from embryos in which the signaling pathway was inac-
A
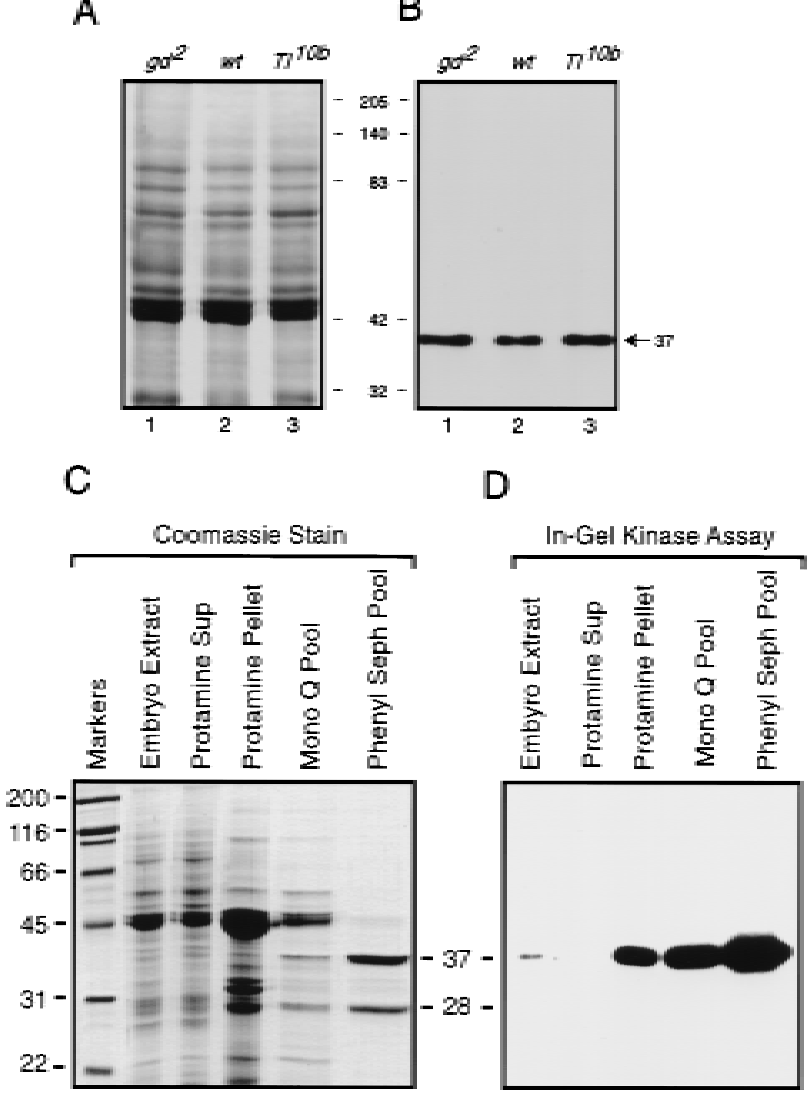

Figure 1. In-gel kinase assay allows identification and purification of a Cactus kinase in embryonic extracts. (A) Coomassiestained SDS-polyacrylamide gel loaded with $20 \mu \mathrm{g}$ of total embryonic protein from $\mathrm{gd}^{2}$ (lane 1), wild-type (lane 2 ), and $\mathrm{TI}^{10 \mathrm{~b}}$ (lane 3). (B) In-gel kinase assay. Embryonic proteins corresponding to those in the Coomassie-stained gel were subjected to electrophoresis and a subsequent in-gel kinase assay in an $8 \%$ SDS-polyacrylamide gel that was polymerized in the presence of $40 \mu \mathrm{g} / \mathrm{ml}$ of $\mathrm{His}_{6}-\mathrm{Cactus}$. The [32 $\mathrm{P}$-labeled proteins were then visualized by autoradiography. The sizes of the molecular mass markers between the panels are in kilodaltons. The arrow indicates the position of a Cactus kinase activity $(37,000 \mathrm{mw})$. (C) Coomassie-stained SDS-polyacrylamide gel of fractions from the purification of Cactus kinase CKII. (Lane 1) mw markers; (lanes 2-4) $20 \mu \mathrm{g}$ of protein; (lane 5) $3 \mu \mathrm{g}$ of protein; (lane 6) $2 \mu \mathrm{g}$ of protein. (D) In-gel kinase assay with half as much protein per lane as in the Coomassie-stained gel shown in $\mathrm{C}$.

tive $\left(g d^{2} / g d^{2}\right)$, active only ventrally (wild-type), or constitutively active $\left(\mathrm{TI}^{1 \mathrm{Ob}}\right)$.

By use of extracts from 0- to 16-hr wild-type embryos as the kinase source and GST-Cactus as the substrate, we developed a three-step procedure for purifying the Cactus kinase to $>95 \%$ homogeneity (Fig 1C). The purified kinase has 28,000 and 37,000 mw subunits, of which only the latter has detectable kinase activity (Fig. 1D). Amino-terminal protein sequencing of the catalytically active kinase subunit reveal ed that the first 15 residues were identical to those of the $37,000 \mathrm{mw}$ catalytic, or $\alpha$, subunit of CKII (Saxena et al. 1987). The apparent mw $(28,000)$ of the other subunit in our preparation matches 
that of the regulatory, or $\beta$, subunit of CKII. Furthermore, the Cactus kinase activity and the two enzyme subunits elute from a gel filtration column with an apparent mw of 130,000 (data not shown), consistent with the previous finding that native CKII is an $\alpha_{2} \beta_{2}$ tetramer (Glover et al. 1983).

\section{CKII phosphorylates serine residues in the Cactus} PEST domain

CKII can modify both serine and threonine residues. To identify which side chains in Cactus are phosphorylated by CKII, we incubated a Cactus fusion protein with the purified kinase in the presence of $\left[\gamma^{-32} \mathrm{P}\right] \mathrm{ATP}$ and then carried out two-dimensional phosphoamino acid analysis. As shown in Figure 2A, CKII phosphorylates GSTCactus exclusively at serine residues.

In determining which serine residues in Cactus were the sites of CKII phosphorylation, we began by carrying out deletion mapping in combination with a liquidphase kinase assay. These experiments revealed that CKII fails to phosphorylate a Cactus protein lacking amino acids 458-501 (Fig. 2B, lane 2). This truncated Cactus protein, referred to as Cact $^{\triangle P E S T}$, lacks the PEST domain, as well as 24 residues carboxy-terminal to this domain (Fig. 2C).

$\mathrm{N}$ ext, we used site-directed mutagenesis to determine whether CKII phosphorylation occurred specifically within the PEST domain. Four serine residues lie within the region deleted in the $\mathrm{Cact}^{\triangle \mathrm{PEST}}$ protein; three of these lie within the PEST domain itself (Fig. 2C). In generating the cact ${ }^{\mathrm{CSA} 3}$ construct, we mutated the codons encoding the PEST domain serines (Ser-463, Ser-467, and Ser-468), converting these three resi dues to al anines. We mutated Ser-490, carboxy-terminal to the PEST domain, independently, to produce cact ${ }^{\mathrm{CSA} 1}$. The cSA 3 mutation blocked Cactus phosphorylation by CKII in vitro, whereas the cSA 1 mutation had no detectable effect (Fig. 2B, lanes 3,5). Thus, CKII phosphorylation of Cactus in vitro is restricted to the three serines, or a subset thereof, within the Cactus PEST domain. Two of these serines, Ser-463 and Ser-468, lie within a consensus CKII phosphorylation site: $S / T \times X D / E$, in which $X$ represents any nonbasic amino acid (Pinna 1990).

The Cactus PEST domain CKII sites are phosphorylated in vivo

N ext, we investigated whether the CKII sites in the Cactus PEST domain are phosphorylated in developing embryos. By comparing the ability of CKII to phosphorylate untreated and phosphatase-treated Cactus from embryos, we could specifically assay to what extent the Cactus CKII sites were modified in vivo.

Immunoprecipitates from embryonic extracts were incubated with or without alkaline phosphatase (CIP), then treated with purified CKII in the presence of $[\gamma$ ${ }^{32}$ P]ATP. We subjected the reaction products to electrophoresis in an SDS-polyacrylamide gel, transferred the resolved proteins to a polyvinylidene difluoride (PVDF) membrane, and used the membrane for immunoblotting with anti-Cactus antibodies (Fig. 3A) and for autoradiography (Fig. 3B).

Cactus protein from wild-type embryos was phosphorylated by CKII to an appreciable extent only after phosphatase treatment (Fig. 3B, Ianes 2,4). The same was true for C actus from gd $^{2}$ embryos (Fig. 3B, lanes 5,6). We conclude that most, if not all, Cactus in embryos is phosphorylated at the CKII sites, regardless of the state of the dorsoventral signaling pathway.
A

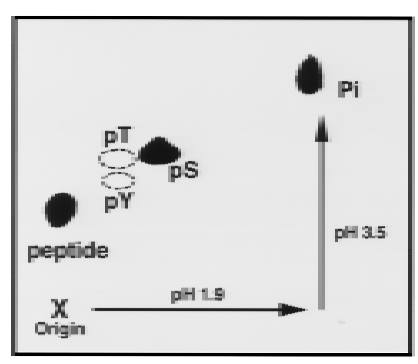

C
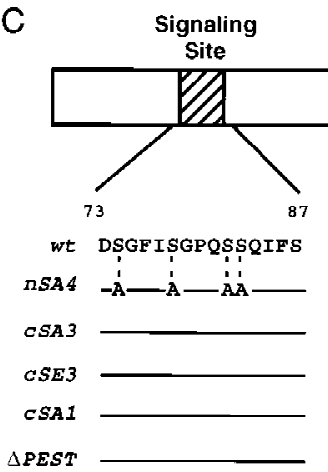

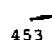

453

$\$$
$\$$
$\$$
$\$$
$\$$
$\$$

B

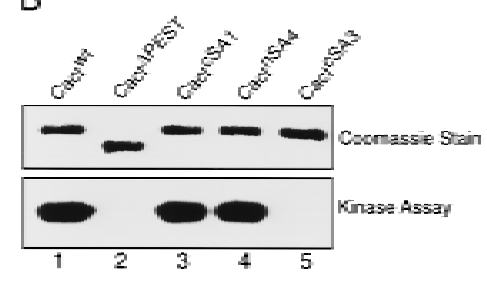

Ankyrin Repeats

RGAETVTPPDSDYDSSDIEDLDDTKMYDR .

481 PEST

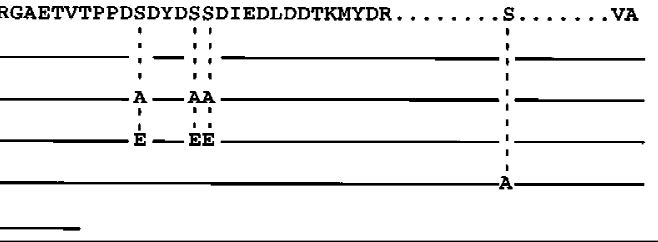

Figure 2. Mapping the phosphorylation sites in Cactus. (A) Phosphoamino acid analysis of Cactus protein phosphorylated in vitro with partially purified CKII. Standards [(pS) phosphoserine; (pT) phosphothreonine; (pY) phosphotyrosine] were visualized by ninhydrin stain; ${ }^{32} \mathrm{P}$-labeled amino acids were detected by autoradiography. The positions of free phosphate, partially digested polypeptides, and the sample origin are indicated. (B) GSTtagged wild-type and mutant Cactus isoforms ( $200 \mathrm{ng}$ each) were used as substrates in in vitro kinase assays with purified CKII. Total protein was stained (top) before being visual ized by autoradiography (bottom). (C) Schematic representation of Cactus. N umbers indicate position in the amino acid sequence. Amino acid substitutions in each Cactus mutant are indicated by the dashed lines. 


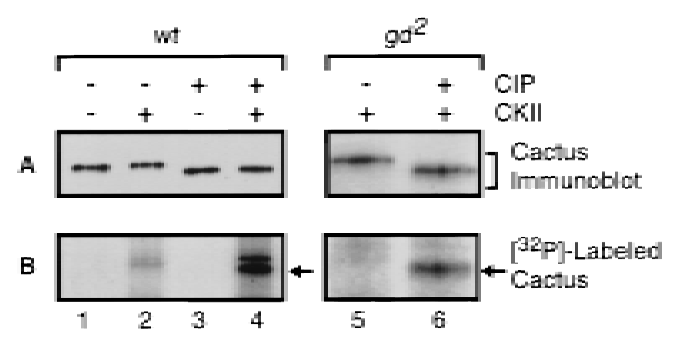

Figure 3. The CKII sites are phosphorylated in vivo. The immunocomplexes generated with anti-Dorsal serum and $5 \mathrm{mg}$ of $0-3 \mathrm{hr}$ wild-type or $\mathrm{gd}^{2}$ embryonic extracts were incubated with (lanes $3,4,6$ ) or without (lanes 1,2,5) calf alkaline phosphatase (CIP). The immunoprecipitates were then washed with kinase buffer and further incubated in the presence of $\left[\gamma^{3}{ }^{32} \mathrm{P}\right] \mathrm{ATP}$ with (lanes 2,4,5,6) or without (lanes 1,3) purified CKII. The resolved proteins were transferred to a PVDF membrane for immunoblotting with anti-Cactus antibodies (top) and autoradiography (bottom).

The experiments presented in Figure 3 also provided evidence that CKII is not the only Cactus kinase in embryos. Phosphatase treatment increased the electrophoretic mobility of embryonic Cactus protein (Fig. 3A, Ianes 1,2 vs. lanes 3,4 ), yet phosphorylation of Cactus by CKII did not substantially counteract this effect (Fig. 3A, Ianes 2,4$)$. Thus, Cactus is phosphorylated in vivo at one or more sites other than the sites of CKII modification. In this regard, we have previously identified four serine residues in the amino terminus of Cactus as the probable sites of signal-inducible phosphorylation (Reach et al. 1996).

Mutation of the CKII phosphorylation sites alters Cactus function in vivo

N ext, we used an RN A microinjection assay to ascertain whether the CKII phosphorylation sites in the Cactus carboxyl terminus influence dorsoventral patterning. Mutant forms of Cactus expressed from microinjected RNA can compete with endogenous Cactus and inhibit signaling (Belvin et al. 1995; Bergmann et al. 1996; Reach et al. 1996). Such inhibition prevents Dorsal nuclear translocation, resulting in a dorsalization that reflects a loss of ventral and lateral fates and an expansion of dorsal ones. This change in cell fates is apparent both as a decrease in the percentage of embryos that hatch into larvae and as an alteration in the cuticle of the unhatched embryos.

Four degrees of dorsalization can be distinguished by examining the cuticle of unhatched embryos (Roth et al. 1991; Chasan and Anderson 1993). $\mathrm{A}_{3}$ cuticle, the most mildly affected, has wild-type elements, but is curled up on itself because of a partial loss of the ventrally derived mesoderm. The more severely affected $D_{2}$ and $D_{1}$ cuticles are characterized by a reduction or loss, respectively, of the ventral denticl e belts. The absence of signal transduction results in a completely dorsal ized or $D_{0}$ cuticle, a twisted tube of epidermis lacking not only the ventral denticle bel ts but also the dorsolaterally derived Filzkörper.
RNAs corresponding to $\mathrm{Cact}^{\mathrm{CSA} 3}$ were injected into the posterior end of wild-type stage 2 embryos, prior to the initiation of intracellular dorsoventral signaling. Forty-two percent of the injected embryos failed to hatch and many of these exhibited $\mathrm{aD}_{3}$ phenotype (Table 1 ). In contrast, microinjection of cact ${ }^{\text {wt }}$ RNA had no detectable effect on viability, as evidenced by a hatch rate equival ent to that of embryos injected with buffer al one (94\% vs. $90 \%$; Table 1). Thus, a Cactus protein mutant for the three PEST domain serines decreased the efficiency of signaling to Dorsal in the embryo.

The phenotypic consequence of mutating the CKII sites in the Cactus PEST domain, although significant, was less severe than the effect of deleting the PEST region altogether. Parallel injection experiments carried out with cact ${ }^{\triangle P E S T}$ RN A resulted in a $0 \%$ hatch rate and a $D_{2}$ phenotype (Table 1). Thus, as noted previously (Bel vin et al. 1995; Bergmann et al. 1996), Cactus lacking the PEST domain interferes substantially with dorsoventral signaling in a wild-type embryo.

The function of the PEST domain CKII sites is distinct from that of the signal acceptor sites in the Cactus amino terminus

To compare further the effect of mutating the Cactus CKII sites with del etion of the Cactus PEST domain, we combined the CSA3 and $\triangle \mathrm{PEST}$ mutations with the amino-terminal SA4 mutation, in which Ser-74, Ser-78, Ser-82, and Ser-83 are converted to alanines (Fig. 2C). We have shown previously that this mutation, hereafter termed nSA4, blocks signal-mediated degradation of Cactus (Reach et al. 1996).

As shown in Table 1 and Figure 4, the CSA 3 mutation significantly enhanced the dominant-negative effect of nSA 4 on dorsoventral signaling. By itself, the nSA4 mutation reduced the hatch rate of injected embryos in this assay threefold (Table 1 ) and resulted in phenotypes as severe as $\mathrm{D}_{2}$ (Fig.4, cf. $\mathrm{C}$ to $\mathrm{A}$ ). In contrast, the cact $^{\mathrm{nSA} 4, \mathrm{CSA} 3}$ double mutant lowered the hatch rate an

Table 1. Phenotypic effects of wild-type and mutant cactus RNA injected into wild-type embryos

\begin{tabular}{lccc}
\hline RN A injected & $\begin{array}{c}\text { Embryos } \\
\text { hatched }(\%)\end{array}$ & $\begin{array}{c}\text { Extent of } \\
\text { dorsalization }\end{array}$ & $\begin{array}{c}\text { Embryos } \\
\text { scored (no.) }\end{array}$ \\
\hline none & 90 & none & 42 \\
cact $^{\text {Wt }}$ & 94 & none & 63 \\
cact $^{\text {CSA3 }}$ & 58 & $\mathrm{D}_{3}$ & 53 \\
cact $^{\text {PEST }}$ & 0 & $\mathrm{D}_{2}$ & 48 \\
cact $^{\text {DSA4 }}$ & 30 & $\mathrm{D}_{2}$ & 130 \\
cact $^{\text {nSA4, cSA3 }}$ & 3 & $\mathrm{D}_{1}$ & 118 \\
cact $^{\text {CSE3 }}$ & 87 & none & 55 \\
cact $^{\text {nSA4, cSE3 }}$ & 73 & $\mathrm{D}_{3}$ & 112 \\
\hline
\end{tabular}

RNA transcripts were produced in vitro and injected at a concentration of $2 \mu \mathrm{g} / \mu \mathrm{l}$ into stage-2 embryos obtained from wildtype females. For nonhatching larvae, a subset of cuticles were obtained and examined around the site of microinjection; the extent of dorsalization represents the most severe phenotype detected. (cact ${ }^{\mathrm{wt}}$ ) Wild-type cactus. 

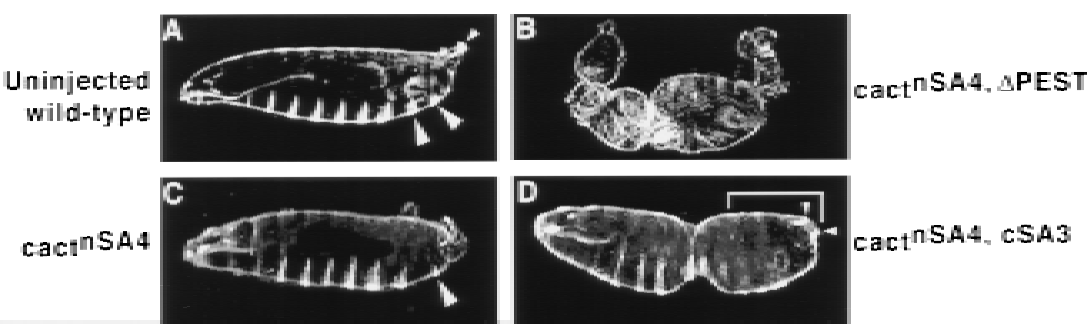

Figure 4. Mutation of the sites necessary for CKII phosphorylation of Cactus in vitro alters Cactus activity in vivo. Darkfield micrographs are shown of cuticles (anterior left; ventral bottom) derived from uninjected wild-type embryos (A) or wild-type embryos injected with $2 \mathrm{mg} / \mathrm{ml}$ of RNA at the posterior end (B-D). (A) N o RN A. Eight abdominal ventral denticlebelts are evident (the two posterior-most denticle belts are highlighted by the large arrowheads), as is the dorsolateral ly derived Filzkörper apparatus at the posterior end (small arrowhead). (B) cact ${ }^{\text {nSA } 4, \triangle P E S T}$ RN A. Complete dorsal ization ( $D_{0}$ phenotype) is apparent, with all ventral and lateral cuticle el ements missing. (C) cact ${ }^{\text {nSA } 4}$ RN A. One of the two posterior-most ventral denticle belts is absent with the remaining belt significantly reduced in size (large arrowhead; $D_{2}$ phenotype). (D) cact $^{\mathrm{nSA} 4, \mathrm{CSA} 3}$ RN A. The posterior ventral denticle belts are missing from the cuticle (del ineated by the white bracket), but the Filzkörper are present (small arrowheads; $D_{1}$ phenotype).

additional 10-fold relative to wild-type and resulted in $\mathrm{D}_{1}$ cuticles (Fig. 4D). As in the single-mutant studies, however, the cSA3 mutation had a less severe effect than did deletion of the entire PEST domain. Microinjection of cact $^{\mathrm{nSA} 4, \triangle \mathrm{PEST}} \mathrm{RN} A$ resulted in $\mathrm{D}_{0}$ cuticles lacking all ventral denticle belts as well as the Filzkörper (Fig. 4B). These results show that CKII-mediated phosphorylation contributes to, but is not a strict prerequi site for, Cactus PEST domain function.

Glutamate substitutions in the CKII sites suppress the dominant inhibitory effect of cact $^{\text {nSA } 4}$

A reasonable interpretation of our results is that the serine-to-alanine substitutions in $\mathrm{Cact}^{\mathrm{cSA} 3}$ block phosphorylation by CKII and thereby alter the activity of Cactus in vivo. If so, conversion of the PEST domain serines to gl utamate residues might affect Cactus in an altogether different manner. Although the glutamic acid side chains would block phosphorylation by CKII, their negative charge might serve as a mimetic replacement for the phosphate groups introduced into wild-type Cactus by CKII. Therefore, we generated the cact ${ }^{\mathrm{CSE} 3}$ construct, in which codons 463,467 , and 468 encode glutamic acid residues.

By itself, cact ${ }^{\mathrm{CSE3}} \mathrm{RN}$ A did not interfere with signaling (Table 1). Embryos injected with cact ${ }^{\text {CSE3 }}$ RNA had a hatch rate $(87 \%)$ comparable with that observed for embryos injected with buffer alone $(90 \%)$. Thus, as predicted, Cact ${ }^{\text {SEE3 }}$ behaved much more like wild-type Cactus than like Cact $^{\text {cSA } 3}$.

When combined with nSA4, the CSE3 mutation differed in phenotype not only from the nSA 4,CSA 3 double mutant but also the nSA 4 single mutant. Only about one-fourth of the embryos injected with cact ${ }^{\text {nSA 4,CSE3 }}$ RNA failed to hatch and none exhibited a phenotype more severe than $\mathrm{D}_{3}$ (Table 1). Thus, the cSE3 mutation suppressed the nSA 4 phenotype.

Mutation of the CKII phosphorylation sites in Cactus does not alter association with Dorsal

The fact that Cact $^{\mathrm{CSA} 3}$ is similar in phenotype to Cact $^{\triangle P E S T}$ suggested that CKII-mediated phosphorylation of Cactus enhances PEST-mediated protein turnover. Nonetheless, it remained possible that modification of the CKII sites in $\mathrm{Cact}^{\mathrm{CSA} 3}$ altered the interaction of Cactus with Dorsal. Therefore, we used proteins translated in vitro to assay the binding of wild-type and mutant Cactus isoforms to Dorsal.

Approximately $10 \mathrm{fmoles}$ of unlabeled Dorsal protein was mixed with varying amounts of ${ }^{35} \mathrm{~S}$-labeled $\mathrm{C}$ actus isoforms and the resulting complexes separated on $5 \%$ native polyacrylamide gels. When four fmoles of ${ }^{35} \mathrm{~S}$ Cactus was added to the binding reaction, we detected two radiolabeled species (Fig. 5A). The faster migrating species consisted of free Cactus. The slower migrating complex contained Dorsal as well as Cactus, as confirmed by immunoblot experiments with anti-Dorsal antibodies and by a parallel protein association assay with ${ }^{35} \mathrm{~S}$-labeled Dorsal and unlabeled Cactus (data not shown). On the basis of the pl of each protein and the mobility of Dorsal monomers and dimers (Fig. 5A), we deduced that the slower migrating species contained two Dorsal molecules and one Cactus ( $\left.\mathrm{DI}_{2}-\mathrm{Cact}\right)$. Such a complex has been detected in embryos (Isoda and $\mathrm{N}$ üsslein-Vol hard 1994), where the ratio of Cactus to Dorsal is comparable with that used here.
A.

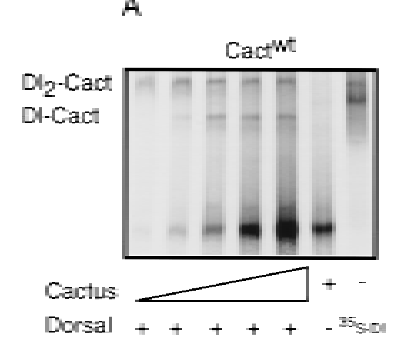

B

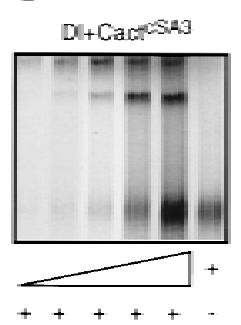

C

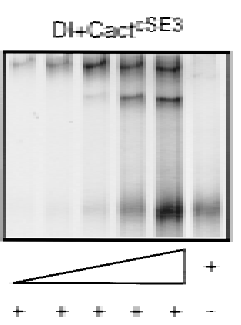

D

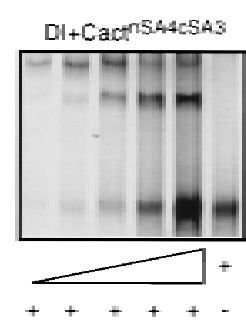

Figure 5. Association of Dorsal with wildtype and mutant Cactus. A constant amount of unlabeled Dorsal was mixed with increasing amounts of ${ }^{35} \mathrm{~S}-$ labeled $\mathrm{Cact}^{\mathrm{wt}}$ (A), $\operatorname{Cact}^{\mathrm{cSA} 3}$ (B), $\mathrm{Cact}^{\mathrm{cSE} 3}$ (C), and $\mathrm{Cact}^{\mathrm{nSA4,CSA3}}$ (D). Bands corresponding to free Cactus and two Dorsal-Cactus complexes are indicated. The mobility of ${ }^{35} \mathrm{~S}$-labeled Dorsal species resolved in the absence of Cactus is shown in the extra lane in A. 


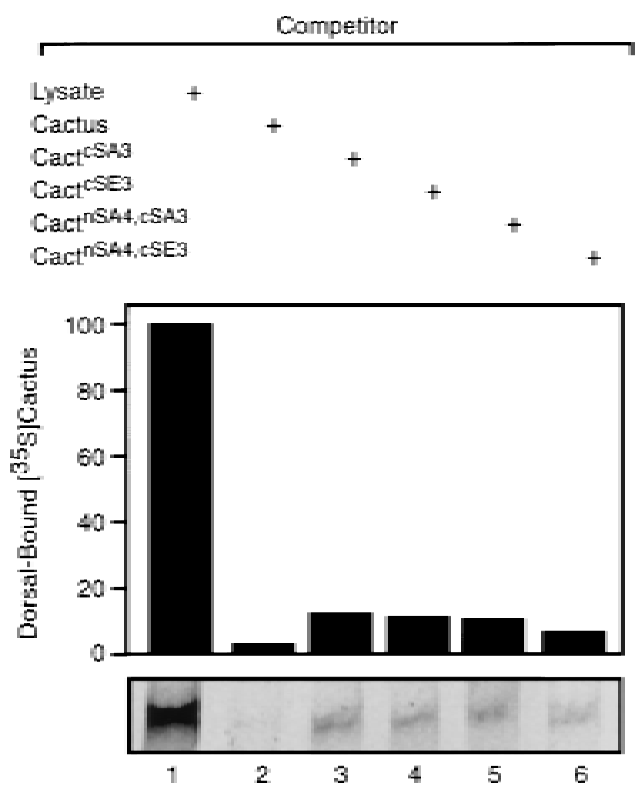

Figure 6. Competition between Dorsal-bound wild-type ${ }^{35} \mathrm{~S}$ labeled Cactus and mutated Cactus proteins. Ten femtomoles of unlabel ed Dorsal and 10 fmoles of ${ }^{35} \mathrm{~S}$-label ed wild-type Cactus were mixed with reticulocyte lysate al one (lane 1 ) or with Iysate containing a 20-fold excess of Cact ${ }^{\text {wt }}$ (lane 2), Cact ${ }^{\mathrm{CSA}} 3$ (lane 3), Cact ${ }^{\text {cSE3 }}$ (lane 4), Cact ${ }^{\text {nSA 4, cSA3 }}$ (lane 5), or Cact ${ }^{\text {nSA 4, CSE3 }}$ (lane 6). The amounts of Dorsal-bound Cactus were visualized by autoradiography (bottom) and quantitated to construct the bar graph (arbitrary units).

When we added more Cactus to the binding assay, we detected increasing amounts of a third species that contained both Dorsal and Cactus. This species had a mobility greater than that of $\mathrm{DI}_{2}-\mathrm{Cact}$, but still appreciably slower than that of free Cactus. Therefore, we believe that this species contains one molecule each of Dorsal and Cactus (DI-Cact).

The wild-type and mutant forms of Cactus exhibited similar affinities for Dorsal. Cactus isoforms in which the three serines in the PEST domain had all been mutated to either al anine (Cact ${ }^{\mathrm{CSA} 3}$ ) or glutamate (Cact ${ }^{\mathrm{CSE3}}$ ) bound Dorsal to the same extent as wild-type Cactus (Fig. 5B,C). The same was true for Cact ${ }^{\mathrm{nSA} 4, \mathrm{CSA} 3}$ (Fig. 5D).

The mutant $C$ actus proteins also displayed wild-type activity in a competition assay (Fig. 6). In these experiments, Dorsal association with label ed Cactus was initiated in the presence of a 20-fold excess of an unlabeled Cactus isoform. Wild-type and mutant Cactus proteins did not differ significantly in their ability to compete with ${ }^{35} \mathrm{~S}$-labeled wild-type Cactus for binding to Dorsal (Fig. 6). We conclude that modification of the CKII sites in the Cactus PEST region does not appreciably affect the association of Cactus with Dorsal.

Mutation of the CKII phosphorylation sites alters Cactus protein levels in vivo

Having found that $\mathrm{Cact}^{\mathrm{wt}}$, Cact ${ }^{\mathrm{cSA} 3}$, and $\mathrm{Cact}^{\mathrm{CSE} 3}$ bound Dorsal with comparable affinities, we set out to directly assay whether the CSA 3 and CSE3 mutations al tered Cactus accumulation in vivo. We generated RNA by transcription in vitro of HA-tagged versions of cact ${ }^{\text {wt }}$, cact $^{\mathrm{CSA} 3}$, or cact $^{\mathrm{CSE} 3}$, injected these RNAs into stage 2 embryos, and allowed development to continue until stage 4. We then extracted total embryonic contents with a microinjection needle and analyzed the levels of the hemagglutinin (HA)-tagged Cactus isoforms by immunoblotting.

As shown in Figure 7, $\mathrm{HA}-\mathrm{Cact}^{\mathrm{CSA} 3}$ accumulated to a substantially higher level than HA-Cact ${ }^{\text {wt }}$, whereas much less HA-Cact ${ }^{\mathrm{CSE}}$ was present than the wild-type isoform. Thus, there was a close correlation in vivo between the activity and amount of the three Cactus isoforms. These results provide strong support for the hypothesis that phosphorylation of Cactus by CKII enhances PEST domain function in promoting protein turnover.

\section{Discussion}

Wild-type activity of the Cactus PEST domain in embryos requires phosphorylation by CKII

We have shown that Drosophila CKII phosphorylates Cactus in vitro and that Cactus is phosphorylated in vivo at the CKII sites at the time of dorsoventral signaling. We conclude that CKII phosphorylates the Cactus PEST domain in embryos, while recognizing that a definitive proof of this hypothesis awaits isolation and characterization of CKII mutations. We also find evidence for phosphorylation of Cactus at other sites, consistent with our previous findings (Reach et al. 1996). Our failure to detect additional Cactus kinases in the in-gel assay may indicate that such kinases are much less abundant than CKII, that they are only active as multimers, or that they fail to recognize bacterially expressed Cactus as a substrate.

Cact $^{\triangle \mathrm{PEST}}$ and Cact ${ }^{\mathrm{CSA}}$, but not wild-type Cactus or Cact ${ }^{\mathrm{CSE3}}$, interfered with signaling when introduced into wild-type embryos. We, and others, have shown previously that Cact $^{\triangle P E S T}$ accumulates at the expense of wildtype Cactus (Belvin et al. 1995; Reach et al. 1996); here

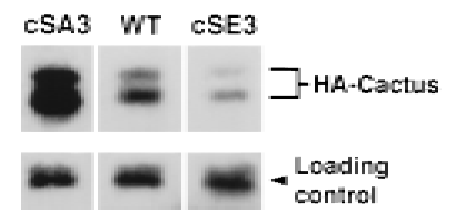

Figure 7. The CSA 3 and CSE3 mutations affect Cactus protein levels in vivo. Wild-type stage 2 embryos were microinjected with the indicated HA-tagged cactus-encoding RNA and allowed to devel op to stage 4 . Total embryonic extracts were then collected by microextraction and examined by immunoblotting with anti-HA antibody. The membrane was then immediately reprobed for a biotinylated embryonic protein to control for loading (Reach et al. 1996). Two isoforms of HA-Cactus are visible, as also observed for endogenous Cactus (Belvin et al. 1995; Reach et al. 1996). 
we have shown that the cSA3 mutation also leads to higher levels of Cactus in embryos, whereas the cSE3 reduces the amount of protein that accumulates. N either substitution mutation, however, disrupts the binding of Cactus to Dorsal.

We interpret these experiments as follows: Cactus protein deleted for the PEST domain (Cact ${ }^{\triangle \mathrm{PEST}}$ ) or lacking the negative charges introduced by CKII-mediated phosphorylation ( $\mathrm{Cact}^{\mathrm{CSA} 3}$ ) has a longer half-life than endogenous Cactus. As a result, Cactus accumulates above wild-type levels, interfering with signal transduction. In contrast, exogenous wild-type Cactus, like the endogenous protein, is efficiently degraded and, consequently, has no effect on signaling. Cactus in which the PEST domain is not phosphorylated but is nonetheless negatively charged (Cact ${ }^{\mathrm{CSE}}$ ) is al so efficiently degraded and does not, therefore, alter Dorsal gradient formation.

We believe that differential effects on PEST function al so underlie the enhancement of nSA 4 seen with $\triangle P E S T$ and CSA 3, as well as the suppression observed with cSE3. In the experiments described here, the relative half-lives of wild-type Cactus and Cactus mutant for the nSA 4 site determined the degree of dorsalization. As a result, the dominant interfering activity of $\mathrm{Cact}^{\mathrm{nSA} 4}$ was increased by the mutations blocking PEST-mediated turnover and decreased by the gl utamate substitutions that apparently promote PEST-dependent proteolysis.

Given that the sites of CKII phosphorylation are occupied in vivo, it may seem paradoxical that substitution of glutamic acid residues for the three PEST domain serines increases PEST-mediated proteolysis. A likely explanation is that the CSE3 mutation acidifies the PEST domain to a greater extent than does CKII-mediated phosphoryIation. Only two of the three PEST domain serines reside in a consensus CKII phosphorylation site. Furthermore, although we find that mutation of any single PEST domain serine does not eliminate CKII-mediated phosphorylation of Cactus (data not shown), Gay and colleagues have recently found that Ser-468 is the predominant site of modification in vitro (Packman et al. 1997). We expect, therefore, that CKII phosphorylation introduces less negative charge than three serine-to-glutamate substitutions.

Taken together, our results shows that generation of a fully functional Cactus PEST domain requires CKII-catalyzed phosphorylation. Furthermore, in light of the fact that PEST-mediated turnover of Cactus is essential for wild-type signal transduction (Belvin et al. 1995; Bergmann et al. 1996; Table 1), these results also indicate that CKII plays an essential role in wild-type patterning of the Drosophila embryo.

The role of PEST-mediated proteolysis in dorsoventral patterning

In the absence of Toll-mediated signaling, the steadystate level of Cactus in embryos is maintained by an equilibrium between synthesis and degradation of free Cactus. That injection of cactus antisense RN A phenocopies a loss of cactus function indicates that translation of Cactus is required to maintain Dorsal in the embryonic cytoplasm (Geisler et al. 1992). That free Cactus undergoes signal-independent degradation is evident from the phenotype of dorsal null mutants, which, although wild-type for the cactus locus, do not accumulate any Cactus protein. As a result of the synthesis and degradation of free Cactus, the level of Cactus in the embryo closely parallels that of Dorsal (Whalen and Steward 1993; Bergmann et al. 1996).

It is essential that the levels of Dorsal and Cactus be in balance. If there is too little Cactus, as in embryos derived from cactus mutant mothers, Dorsal translocates into dorsal as well as ventral nuclei (Roth et al. 1991). If there is too much Cactus, as in embryos expressing Cact $^{\text {PEST, }}$ the shape of the gradient is al so al tered (Belvin et al . 1995). The mechanism that has evolved to achieve this balance is simple: Any Cactus protein not bound to Dorsal is degraded (Whalen and Steward 1993). This process is evidently quite efficient, because neither microinjection of large amounts of cact ${ }^{\text {wt }}$ RN A nor a twofold alteration in the gene dosage of Cactus or Dorsal has adverse effects on embryonic development (Table 1; Govind et al. 1993).

The decrease in the slope of the Dorsal gradient seen on introduction of $\mathrm{Cact}^{\triangle \mathrm{PEST}}$ into embryos indicates an inefficient degradation of Dorsal-Cactus or Dorsal$\mathrm{Cact}^{\triangle \mathrm{PEST}}$ complexes in these embryos. This may reflect an ability of free Cact $^{\triangle P E S T}$ to serve as a sink for the signaling machinery, as has been suggested previously (Belvin et al. 1995; Bergmann et al. 1996; Reach et al. 1996). Our results here suggest an additional explanation. When the ratio of Dorsal to wild-type or mutant Cactus in our in vitro binding experiments was comparable with that in embryos, Dorsal bound its inhibitor with a 2:1 stoichiometry. At higher concentrations of Cactus, however, we detected a complex containing one molecule each of Cactus and Dorsal, a configuration not found in wild-type embryos (Isoda and N üsslein-Volhard 1994). If high concentrations of $\mathrm{Cact}^{\triangle \mathrm{PEST}}$ al so drive formation of Cact-DI complexes in vivo, such complexes might differ in their response to Toll-mediated signaling and thereby disrupt signal transduction to Dorsal.

\section{CKII phosphorylation may play a general role in PEST} domain function

The carboxy-terminal PEST domain of the mammalian Cactus counterpart I $\mathrm{KB}_{\alpha}$ is also phosphorylated by CKII (Barroga et al. 1995). This modification is required for degradati on of $I_{\kappa} B \alpha$ in an in vitro assay (M cElhinny et al. 1996). Furthermore, mutations in the CKII sites alter $1 \kappa \mathrm{B} \alpha$ stability in transfected cells (Lin et al. 1996; Schwarz et al. 1996). It is not known, however, whether phosphorylation of $I_{\kappa} B \alpha$ by CKII is required for wild-type signaling to NF- $\mathrm{B}$. In the case of $I \kappa B \beta, C K I I$ modification of the PEST domain alters its ability to bind and inhibit c-rel (Chu et al. 1996), unlike what we observe for Cactus and Dorsal.

Consideration of the sequence composition of PEST domains indicates that CKII might have a general role in 
PEST domain function. In their original presentation of the PEST hypothesis (Rogers et al. 1986), Rechsteiner and coll eagues noted that many PEST sequences contain potential sites for phosphorylation by casein kinases. By their very definition, PEST domains contain serine and threonine residues in close proximity to acidic side chains, very frequently resulting in one or more consensus sites for phosphorylation by CKII.

$M$ ann and colleagues have recently shown that CKII phosphorylates the Drosophila Antennapedia protein (Jaffe et al. 1997). They have mapped the two predominant sites of CKII phosphorylation and shown that mutations in these sites alter Antennapedia behavior in vivo. In light of our findings, we have searched the Antennapedia sequence for PEST domains and find a predicted PEST domain (residues 359-379) that contains one of the two sites of CKII phosphorylation (Ser-364). Therefore, it may be that Antennapedia, like Cactus, is subject to CKII- and PEST-mediated proteolysis. We note, however, that other Drosophila proteins, for example, Dishevelled, as well as many vertebrate transcription factors and signaling proteins, for example, cJun and protein phosphatase 2A, are phosphorylated by CKII yet lack recognizable PEST domains (Lin et al. 1992; Willert et al. 1997; Hériché et al. 1997).

PEST sequences are present in many classes of proteins, including metabolic enzymes, transcription factors, protein kinases, protein phosphatases, and cyclins. Given that PEST sequences are often conditional proteoIytic signals (Rechsteiner and Rogers 1996) and that the sequence and activity of CKII have been highly conserved during evol ution (Saxena et al . 1987), CKII might serve as a general regulator of PEST-mediated protein degradation.

A difficulty in proposing CKII as a regulator of PEST function is the lack of evidence for modulation of CKII specific activity in vivo (Meisner and Czech 1991). If CKII activity is constitutive, it could neverthel ess be instrumental in regulation, provided a counterbalancing activity were modulated or access to the phosphorylation site were conditional. For example, the coupling of a basal level of CKII phosphorylation with a regulated phosphatase could provide the basis for controlling PEST function. Alternatively, a protein-protein interaction that occludes a PEST domain could regulate the level of CKII-mediated phosphorylation. Whether mechanisms such as these do regulate protein turnover remains an open question.

\section{Materials and Methods}

In-gel kinase assay

Oregon R was used as the wild-type stock; mutations and balancers are described in FlyBase (http:/ / flybase.bio.indiana.edu). Embryonic extracts were prepared as described by Gillespie and Wasserman (1994). For the in-gel kinase assay (Hibi et al. 1993), total protein $(20 \mu \mathrm{g})$ prepared from $0-3 \mathrm{hr}$ embryos was subjected to el ectrophoresis in an $8 \%$ SDS-polyacrylamide gel that had been polymerized in the presence $40 \mu \mathrm{g}$ of bacterially expressed Cactus (hexahistidinetagged Cactus or GST-Cactus) per milliliter of gel. Following electrophoresis, the gel was washed twice for $30 \mathrm{~min}$ with $50 \mathrm{~mm}$ Tris at $\mathrm{pH} 8$, in $20 \%$ isopropanol, twice for $30 \mathrm{~min}$ with buffer $\mathrm{B}(50 \mathrm{~mm}$ Tris- $\mathrm{HCl}$ at $\mathrm{pH} 7.5,5 \mathrm{~mm} \beta$-mercaptoethanol), and once for $1 \mathrm{hr}$ with $200 \mathrm{ml}$ of buffer $\mathrm{B}$ containing $6 \mathrm{M}$ guani dinium $\mathrm{HCl}$. The proteins in the gel were then renatured overnight at $4^{\circ} \mathrm{C}$ in $200 \mathrm{ml}$ of buffer $\mathrm{B}$ containing $0.05 \%$ Tween 20 . N ext, the gel was incubated in kinase buffer ( $25 \mathrm{~mm}$ HEPES at $\mathrm{pH} 7.9,10 \mathrm{~mm} \mathrm{M} \mathrm{gCl}, 2 \mathrm{~mm}$ $\mathrm{MnCl}_{2}, 25 \mu \mathrm{M}$ ATP) containing $10 \mu \mathrm{Ci}$ of [ $\gamma$ - $\left.{ }^{32} \mathrm{P}\right] \mathrm{ATP}$ per $\mathrm{ml}$ at room temperature for $1 \mathrm{hr}$. This incubation was followed by five washes of $200 \mathrm{ml}$ each with $5 \%$ trichloroacetic acid, $1 \%$ sodium pyrophosphate at room temperature. The gel was then dried and subjected to autoradiography.

\section{Purification of the Cactus kinase}

Protamine sulfate $(\sim 0.1 \mathrm{gram}$ of protamine sulfate/ $3 \mathrm{gram}$ of protein) was added gradually to the clarified embryonic extract at $4^{\circ} \mathrm{C}$. Following an additional $15 \mathrm{~min}$ stirring, the solution was subjected to centrifugation at $39,000 \mathrm{~g}$ for $20 \mathrm{~min}$. The pellet was resuspended in $10 \mathrm{ml}$ of buffer $\mathrm{A}$ ( $10 \mathrm{~mm}$ imidazole at $\mathrm{pH}$ 6.5) containing $2 \mathrm{M} \mathrm{N} \mathrm{aCl}, 0.5 \mathrm{mg}$ of DNase I, and $10 \mathrm{~mm} \mathrm{M} \mathrm{gCl}$. After incubation at room temperature for $1 \mathrm{hr}$, the solution was dialyzed for $4 \mathrm{hr}$ at $4^{\circ} \mathrm{C}$ against 1 liter of buffer A containing 2 $\mathrm{M} \mathrm{NaCl}$, and then overnight against 2 liters of buffer $\mathrm{A}$ containing $0.5 \mathrm{M} \mathrm{N} \mathrm{aCl}$. After removal of insoluble material by centrifugation, the solution was diluted fivefold with buffer $A$.

Fifty milliliters of clarified and diluted dialysate was loaded onto a M ono Q 5/ 5 column (Pharmacia) equilibrated previously with buffer $A$. Bound proteins were el uted with a gradient of $0-1$ $\mathrm{M} \mathrm{N} \mathrm{aCl}$ in Buffer $A$. Fractions containing the CKII activity were pooled and applied to a phenyl-Sepharose HP column (Pharmacia) after addition of ammonium sulfate solution to a final concentration of $0.3 \mathrm{~m}$. The phenyl-Sepharose column was then washed with buffer $\mathrm{A}$ containing $0.3 \mathrm{M}$ ammonium sulfate, and protein was eluted with a descending gradient of $0.3-0 \mathrm{M}$ ammonium sulfate in buffer $A$. Fractions containing kinase activity were collected and pooled.

In vitro kinase assay and phosphoamino acid analysis

GST-Cactus was incubated with purified CKII in $30 \mu \mathrm{l}$ of kinase buffer containing $150 \mathrm{~mm} \mathrm{NaCl}$ and $5 \mu \mathrm{Ci}$ of $\left[\gamma^{-32} \mathrm{P}\right] \mathrm{ATP}$ at $30^{\circ} \mathrm{C}$ for $15 \mathrm{~min}$. The kinase reaction was stopped by the addition of $10 \mu \mathrm{l}$ of $5 \times$ SDS sample buffer and boiling for $3 \mathrm{~min}$. Phosphoproteins were analyzed by SDS-polyacrylamide followed by autoradiography of dried gels. Phosphoamino acid analysis was performed as described previously (Boyle et al. 1991).

\section{Immunoprecipitation}

Frozen, dechorionated 0- to 3-hr embryos were thawed on ice and lysed with a Dounce homogenizer in five volumes of TSA buffer $(10 \mathrm{~mm}$ Tris- $\mathrm{HCl}$ at $\mathrm{pH} 8,140 \mathrm{~mm} \mathrm{NaCl}, 0.025 \%$ sodium azide) containing $1 \%$ Triton $\mathrm{X}-100,1 \%$ bovine hemoglobin, 5 $\mathrm{mm}$ iodoacetamide, $1 \mu \mathrm{m}$ each of aprotinin, pepstatin, and leupeptin, and $1 \mathrm{~mm}$ PMSF. After incubation on ice for $1 \mathrm{hr}$, the lysate was centrifuged at $13,000 \mathrm{~g}$ for $30 \mathrm{~min}$. Five hundred microliters of supernatant was then incubated overnight with 15 $\mu \mathrm{g}$ of the IgG fraction from a polyclonal anti-Dorsal antisera. We used an anti-Dorsal serum in this procedure, because this serum is particularly effective in immunoprecipitating Cactus, all, or nearly all, of which is bound to Dorsal in vivo (Bergmann et al. 1996; Z.-P. Liu, unpubl.). The antibody-protein complexes were recovered on protein A-Sepharose beads (Sigma). 
In vitro dephosphorylation and phosphorylation assay

Immunoprecipitates collected on protein A-Sepharose were washed twice with $1 \mathrm{ml}$ of RIPA buffer, twice with $1 \mathrm{ml}$ of TSA buffer containing $0.1 \%$ Triton $\mathrm{X}-100$ and $0.1 \%$ bovine hemoglobin, once with $1 \mathrm{ml}$ of TSA buffer, and once with $0.5 \mathrm{ml}$ of CIP buffer (NEB). The dephosphorylation reaction was carried out in $50 \mu \mathrm{l}$ of CIP buffer at $37^{\circ} \mathrm{C}$ for $1 \mathrm{hr}$ with 10 units of CIP (NEB). For the phosphorylation reaction, the immunoprecipitates were further washed with $0.5 \mathrm{ml}$ of kinase buffer and incubated with purified CKII in kinase buffer for $30 \mathrm{~min}$ at $30^{\circ} \mathrm{C}$. The complexes were separated on an $8 \%$ SDS-polyacrylamide gel and transferred to PVDF membrane (Immobilon-P, Millipore), then subjected to autoradiography and immunoblotting.

\section{Immunoblotting}

Immunoblot analysis was carried out as described previously (Gillespie and Wasserman 1994), by use of anti-Cactus antibodies directly conjugated to alkaline-phosphatase (Boehringer Mannheim). The antibody-antigen complexes were visualized by a chemiluminescence detection system (Tropix). HA-Cact isoforms were detected with a 1/1000 dilution of High Affinity Monoclonal Anti-HA Antibody (Boehringer Mannheim). Alkaline phosphatase-conjugated goat anti-rat immunoglobulin G (Tropix), was used at a dilution of $1 / 10,000$. To control for loading, the PVDF membrane was reprobed with a 1/5000 dilution of streptavidin-conjugated al kal ine phosphatase (T ago, Inc.). Image analysis was performed with Adobe Photoshop to normal ize loading.

\section{Construct formation}

The wild-type cactus, cact ${ }^{\Delta \mathrm{PEST}}$, cact $^{\mathrm{nSA} 4}$ (formerly cact $^{\mathrm{SA} 4}$ ), and cact ${ }^{\text {nSA 4,APEST }}$ constructs have been described previously (Reach et al. 1996). Site-directed mutagenesis of the wild-type cactus CDNA was used to generate the $\operatorname{cact}^{\mathrm{cSA} 1}$, $\operatorname{cact}^{\mathrm{CSA} 3}$, and cact $^{\mathrm{CSE3}}$ mutations. To generate the HA-tagged constructs, two copies of the HA epitope were introduced onto the amino terminus of Cactus by two rounds of PCR amplification.

\section{Protein expression and purification}

The Hexahisti dine-tagged $\left(\mathrm{His}_{6}\right.$ ) Cactus and GST -tagged Cactus was prepared by growing $B L 21$ (DE3) bacteria at $37^{\circ} \mathrm{C}$ to an $A_{600}$ of 0.8 and inducing with Isopropyl $\beta$-D-thiogalactopyranoside (IPTG) at $0.1 \mathrm{~mm}$. After an additional $4 \mathrm{hr}$ incubation, bacteria were harvested, resuspended in $1 / 200$ volume of PBS, and stored at $-80^{\circ} \mathrm{C}$. $\mathrm{His}_{6}-\mathrm{Cactus}$ and $\mathrm{GST}-\mathrm{C}$ actus were purified on $\mathrm{Ni}^{+}-$ NTA and glutathione-agarose columns, respectively.

\section{RNA synthesis, embryo injection, and cuticle preparations}

RNA synthesis and cuticle preparation were performed as described previously (Galindo et al. 1995), except that RNA was purified by RN easy (Qiagen) spin column chromatography. Cuticles were scored for the phenotype exhibited by the region surrounding the posterior site of RNA injection. For immunoblot analysis after RNA microinjection, embryonic contents were collected as described previously (Reach et al 1996).

\section{Protein binding and gel shift assay}

Interaction assays for proteins transl ated in vitro (Promega) contained $0.5 \mu \mathrm{l}$ of unlabeled Dorsal $(\sim 10$ fmoles $)$ and varying amounts (4-60 fmoles) of ${ }^{35} \mathrm{~S}$-label ed Cactus, either wild-type or mutant. Transcription-translations were performed according to manufacturer's protocols with the reticulocyte TNT SP6coupled system from Promega. Each binding reaction was carried out in TSA buffer in a final volume of $13.5 \mu \mathrm{l}$ and was incubated at room temperature for $15 \mathrm{~min}$. The reaction mixture was then loaded onto a 5\% native polyacrylamide gel (37.5: 1 acrylamide/bis ratio) and subjected to electrophoresis in $\mathrm{pH}$ 9.4 buffer ( $60 \mathrm{~mm}$ Tris, $40 \mathrm{~mm} \mathrm{CAPS}$ ) at $4^{\circ} \mathrm{C}$ at $215 \mathrm{~V}$ for $90 \mathrm{~min}$. The gel was then dried and subjected to autoradiography.

\section{Acknowledgments}

We thank Carolyn M oomaw and Clive Slaughter for the aminoterminal sequencing of CKII and Alisha Tizenor for assistance in figure preparation. These studies were supported by grant RO1 GM 50545 from the N ational Institutes of Heal th (N IH) (to S.A.W.) and by stipend support provided by the Robert A. Welch Foundation (to Z.-P.L.) and by an N IH training grant (to R.L.G.).

The publication costs of this article were defrayed in part by payment of page charges. This article must therefore be hereby marked "advertisement" in accordance with 18 USC section 1734 solely to indicate this fact.

\section{References}

Baeuerle, P.A. and D. Baltimore. 1996. NF-кB: Ten years after. Cell 87: 13-20.

Barroga, C.F., J.K. Stevenson, E.M. Schwarz, and I.M. Verma. 1995. Constitutive phosphorylation of $I_{\kappa} B \alpha$ by casein kinase II. Proc. Natl. Acad. Sci. 92: 7637-7641.

Belvin, M.P., Y. Jin, and K.V. Anderson. 1995. Cactus protein degradation mediates Drosophila dorsal-ventral signaling. Genes \& Dev. 9: 783-793.

Bergmann, A., D. Stein, R. Geisler, S. Hagenmaier, B. Schmid, N. Fernandez, B. Schnell, and C. N üsslein-Vol hard. 1996. A gradient of cytoplasmic Cactus degradation establishes the nuclear localization gradient of the dorsal morphogen in Drosophila. Mech. Dev. 60: 109-123.

Boyle, W.J., P. van der Geer, and T. Hunter. 1991. Phosphopeptide mapping and phosphoamino acid analysis by two-dimensional separation on thin-layer cellulose plates. Methods Enzymol. 201: 110-149.

Brown, K., S. Gerstberger, L. Carlson, G. Franzoso, and U. Siebenlist. 1995. Control of $I_{\kappa} B \alpha$ proteolysis by site-specific, signal-induced phosphorylation. Science 267: 1485-1488.

Cao, Z., W.J. Henzel, and X. Gao. 1996. IRAK: A kinase associated with the interleukin-1 receptor. Science 271: 1128-1131.

Chasan, R. and K.V. A nderson. 1993. M aternal control of dorsalventral polarity and pattern in the embryo. In The development of Drosophila melanogaster, (ed. M. Bate and A. Martinez-Arias), pp.387-432. Cold Spring Harbor Laboratory Press, Cold Spring Harbor, NY.

Chu, Z.-L., T.A. MCKinsey, L. Liu, X. Qi, and D.W. Ballard. 1996. Basal phosphorylation of the PEST domain in $I_{\kappa} B \beta$ regulates its functional interaction with the c-rel proto-oncogene product. Mol. Cell. Biol. 16: 5974-5984.

Galindo, R.L., D.N . Edwards, S.K.H. Gillespie, and S.A. Wasserman. 1995. Interaction of the pelle kinase with the membrane-associated protein tube is required for transduction of the dorsoventral signal in Drosophila embryos. Development 121: 2209-2218.

Geisler, R., A. Bergmann, Y. Hiromi, and C. N üsslein-Volhard. 1992. cactus, a gene involved in dorsoventral pattern formation of Drosophila, is related to the $I_{\kappa} B$ gene family of vertebrates. Cell 71: 613-621. 
Gillespie, S.K. and S.A. Wasserman. 1994. Dorsal, a Drosophila Rel-like protein, is phosphorylated upon activation of the transmembrane protein Toll. Mol. Cell. Biol. 14: 3559-3568.

Glover, C.V., E.R. Shelton, and D.L. Brutlag. 1983. Purification and characterization of a type II casein kinase from Drosophila melanogaster. J. Biol. Chem. 258: 3258-3265.

Govind, S., L. Brennan, and R. Steward. 1993. Homeostatic balance between dorsal and cactus proteins in the Drosophila embryo. Development 117: 135-148.

Hériché, J.-K., F. Lebrin, T. Rabilloud, D. Leroy, E.M . Chambaz, and Y. Goldberg. 1997. Regulation of protein phosphatase 2A by direct interaction with casein kinase $2 \alpha$. Science 276: 952-995.

Hibi, M., A. Lin, T. Smeal, A. Minden, and M. Karin. 1993. Identification of an oncoprotein- and UV-responsive protein kinase that binds and potentiates the c-Jun activation domain. Genes \& Dev. 7: 2135-2148.

Isoda, K. and C. N üsslein-Volhard. 1994. Disulfide cross-linking in crude embryonic lysates reveals three complexes of the Drosophila morphogen dorsal and its inhibitor cactus. Proc. Natl. Acad. Sci. 91: 5350-5354.

Jaffe, L., H.-D. Ryoo, and R.S. M ann. 1997. A role for phosphorylation by casein kinase II in modulating A ntennapedia activity in Drosophila. Genes \& Dev. 11: 1327-1340.

Kidd, S. 1992. Characterization of the Drosophila cactus locus and analysis of interactions between cactus and dorsal proteins. Cell 71: 623-635.

Lin, A., J. Frost, T. Deng, T. Smeal, N. al-Alawi, U. Kikkawa, T. Hunter, D. Brenner, and M. Karin. 1992. Casein kinase II is a negative regulator of C-Jun DN A binding and AP-1 activity Cell 70: 777-789.

Lin, R., P. Beauparlant, C. Makris, S. M eloche, and J. Hiscott. 1996. Phosphorylation of $I_{\kappa} B \alpha$ in the C-terminal PEST domain by casein kinase II affects intrinsic protein stability. Mol. Cell. Biol. 16: 1401-1409.

McElhinny, J.A., S.A. Trushin, G.D. Bren, N. Chester, and C.V. Paya. 1996. Casein kinase II phosphorylates $I_{\kappa} B \alpha$ at S-283, S-289, S-293, and T-291 and is required for its degradation. Mol. Cell. Biol. 16: 899-906.

Meisner, H. and M.P. Czech. 1991. Phosphorylation of transcriptional factors and cell-cycle-dependent proteins by casein kinase II. Curr. Opin. Cell Biol. 3: 474-483.

Packman, L.C., K. Kubota, J. Parker, and N .J. Gay. 1997. Casein kinase II phosphorylates $\mathrm{Ser}^{468}$ in the PEST domain of the Drosophila ІкB homologue cactus. FEBS Lett. 400: 45-50.

Palombella, V.J., O.J. Rando, A.L. Goldberg, and T. Maniatis. 1994. The ubiquitin-proteasome pathway is required for processing the NF-kB1 precursor protein and the activation of N F-кB. Cell 78: 773-785.

Pinna, L.A. 1990. Casein kinase 2: An "eminence grise" in cellular regulation? Biochim. Biophys. Acta 1054: 267-284.

Reach, M., R.L. Galindo, P. Towb, J.L. Allen, M. Karin, and S.A. Wasserman. 1996. A gradient of cactus protein degradation establishes dorsoventral polarity in the Drosophila embryo. Dev. Biol. 180: 353-364.

Rechsteiner, M. and S.W. Rogers. 1996. PEST sequences and regulation by proteolysis. Trends Biochem. Sci. 21: 267-271.

Rogers, S.W., R. Wells, and M. Rechsteiner. 1986. Amino acid sequences common to rapidly degraded proteins: The PEST hypothesis. Science 234: 364-368.

Roth, S., Y. Hiromi, D. Godt, and C. N üsslein-Volhard. 1991. cactus, a maternal gene required for proper formation of the dorsoventral morphogen gradient in Drosophila embryos. Development 112: 371-388.

Saxena, A., R. Padmanabha, and C.V. Glover. 1987. Isolation and sequencing of CDN A clones encoding $\alpha$ and $\beta$ subunits of Drosophila melanogaster casein kinase II. Mol. Cell. Biol. 7: 3409-3417.

Schwarz, E.M., D. van Antwerp, and I.M. Verma. 1995. Constitutive phosphorylation of $I_{\kappa} \mathrm{B} \alpha$ by casein kinase II occurs preferentially at serine 293: Requirement for degradation of free $1 \kappa B \alpha$. Mol. Cell. Biol. 16: 3554-3559.

Shelton, C.A. and S.A. Wasserman. 1993. pelle encodes a protein kinase required to establish dorsoventral polarity in the Drosophila embryo. Cell 72: 515-525.

Steward, R. 1987. Dorsal, an embryonic polarity gene in Drosophila, is homologous to the vertebrate proto-oncogene, crel. Science 238: 692-694.

Traenckner, E.B., H.L. Pahl, T. Henkel, K.N. Schmidt, S. Wilk, and P.A. Baeuerle. 1995. Phosphorylation of human $I_{\kappa} B \alpha$ on serines 32 and 36 controls $I_{\kappa} B \alpha$ proteolysis and N F-кB activation in response to diverse stimuli. EMBO J. 14: 28762883.

Van Antwerp, D.J. and I.M. Verma. 1996. Signal-induced degradation of $I_{\kappa} \mathrm{B} \alpha$ : Association with NF-kB and the PEST sequence in $1 \kappa B \alpha$ are not required. Mol. Cell. Biol. 16: 60376045.

Verma, I.M., J.K. Stevenson, E.M. Schwarz, D. Van Antwerp, and S. Miyamoto. 1995. Rel/NF-кB/IкB family: Intimate tales of association and dissociation. Genes \& Dev. 9: 27232735.

Wasserman, S.A. 1993. A conserved signal transduction pathway regulating the activity of the rel-like proteins dorsal and NF-кB. Mol. Biol. Cell 4: 767-771.

Whalen, A.M. and R. Steward. 1993. Dissociation of the dorsalcactus complex and phosphorylation of the dorsal protein correlate with the nuclear localization of dorsal. J. Cell Biol. 123: 523-534.

Willert, K., M. Brink, A. Wodarz, H. Varmus, and R. Nusse. 1997. Casein kinase 2 associates with and phosphorylates Dishevelled. EMBO J. 16: 3089-3097. 


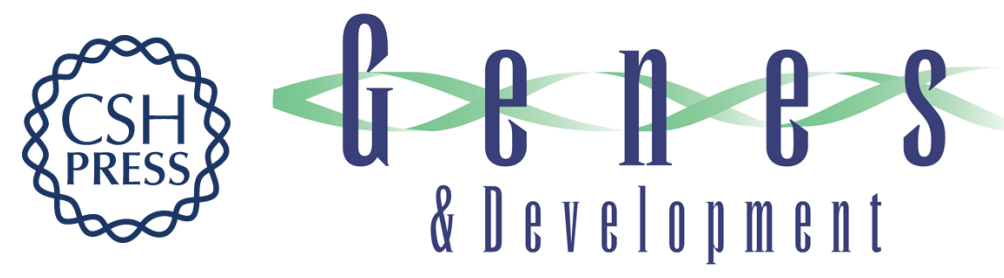

\section{A role for CKII phosphorylation of the Cactus PEST domain in dorsoventral patterning of the Drosophila embryo}

Zhi-Ping Liu, Rene L. Galindo and Steven A. Wasserman

Genes Dev. 1997, 11:

Access the most recent version at doi:10.1101/gad.11.24.3413

References This article cites 39 articles, 25 of which can be accessed free at: http://genesdev.cshlp.org/content/11/24/3413.full.html\#ref-list-1

License

Email Alerting

Receive free email alerts when new articles cite this article - sign up in the box at the top Service right corner of the article or click here.

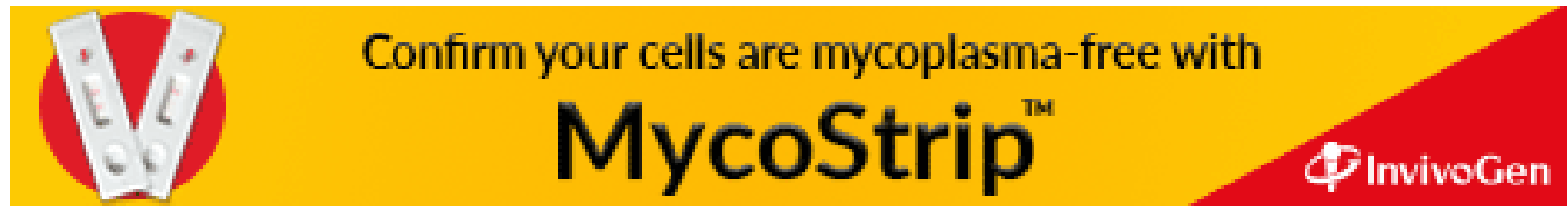

